\title{
Gas phase considerations for the growth of device quality nanocrystalline silicon at high rate
}

\author{
J.K. Rath ${ }^{\mathrm{a}, *}$, A.D. Verkerk ${ }^{\mathrm{a}}$, Y. Liu ${ }^{\mathrm{a}}$, M. Brinza ${ }^{\mathrm{a}}$, W.J. Goedheer ${ }^{\mathrm{b}}$, R.E.I. Schropp ${ }^{\mathrm{a}}$ \\ a Utrecht University, Faculty of Sciences, Nanophotonics-Physics of Devices, P.O. Box 80.000, 3508 TA Utrecht, The Netherlands \\ ${ }^{\mathrm{b}}$ FOM-Institute for Plasma Physics, P.O. Box 1207, 3430 BE Nieuwegein, The Netherlands
}

\section{A R T I C L E I N F O}

\section{Article history:}

Received 9 May 2008

Received in revised form

19 September 2008

Accepted 3 October 2008

\section{Keywords:}

Nanocrystalline silicon

PECVD

Thin film

Solar cell

\begin{abstract}
A B S T R A C T
In order to increase industrial viability and to find niche markets, high deposition rate and low temperature depositions compared to standard deposition conditions are two recent trends in research areas concerning thin film silicon. In situ diagnostic tools to monitor gas phase conditions are useful in quick optimization processes of deposition parameters without going into time consuming material characterizations. Optical emission spectroscopy is an efficient technique to monitor/predict growth rate and phase of the material (amorphous or nanocrystalline). However, at high growth rate conditions which are generally achieved at high chamber pressures $(p)$, the simple correlation breaks down. We see that at high pressure condition a higher $\mathrm{H}_{\alpha} / \mathrm{Si}^{*}$ is needed for the onset of crystallinity than that is found at lower pressure conditions. Additional methods such as estimating the silane depletion from the experiment and the flux ratio of atomic hydrogen to deposited silicon atoms from simulations can be used for fine-tuning the amorphous to nanocrystalline transition regime. On the other hand, intensity of $\mathrm{Si}^{*}$ line loses its character as a monitoring tool for deposition rate. Moreover, the plasma changes its character when the pressure is varied, even when the pd product is kept constant. In situ diagnosis of the ion energy distribution function by a retarding field ion energy analyzer has thrown new lights on the role of hydrogen dilution for depositions at low substrate temperature conditions, namely to compensate the loss in ion energy due to lower gas temperature.
\end{abstract}

(C) 2008 Elsevier B.V. All rights reserved.

\section{Introduction}

For the last several years the photovoltaic market is growing at an average rate of $40 \%$ [1]. Both bulk $\mathrm{Si}$ as well as thin films have increased their markets, however the share of thin film silicon has actually fallen and it is at present around 7\%. The efforts towards thinner wafers, especially for HIT type of cells shown by Sanyo for thicknesses down to $70 \mu \mathrm{m}$ [2] and thin cells $(50 \mu \mathrm{m})$ by transfer technology [3] and the progress in ribbon type silicon technology [4] are going to take away some of the advantages of thin film based solar cells as far as material cost is concerned. On the other hand, thin film silicon solar cells have to also compete with other types of thin film materials such as CdTe and CIS. The recent reports from First Solar (US) indicate that the manufacturing cost of their CdTe based modules reach $\$ 1.25 / \mathrm{Wp}$ [5] and a claimed energy pay back time of 1.1 years. Their expansion to Europe (120MW at Frankfurt (Oder) Germany) puts a chalange to other thin film technology based productions in Europe. CIS technology has brought

\footnotetext{
* Corresponding author. Tel.: +31 30 2532961; fax: +31 302543165

E-mail address: J.K.Rath@uu.nl (J.K. Rath).
}

in new players such as Honda motors (Japan) [6]. Moreover, except for CSG solar [7], all other industries want to use nanocrystalline silicon (nc-Si) in combination with amorphous silicon (a-Si) based cells in a Tandem (so called "micromorph") or triple junction concept (Kaneka Co. [8], Sharp Co. [9], Unisolar Co. [10]) to achieve high stable efficiencies. Hence the deposition rate of both a-Si as well as nc-Si has to be increased substantially compared to the present status at the industries. Several deposition techniques promise to deliver that. However, the thin film Si, especially nc-Si, made by very high frequency plasma enhanced chemical vapour deposition (VHF PECVD) has so far shown the best results, in terms of efficiency as well as deposition rate [11]. This can be attributed to the available ion energy that can be tuned by pressure, coupled power, process temperature, plasma frequency and external applied voltage bias to the RF electrode. Moreover the technique has been used to deposit cells and fabricate modules on flexible plastic substrates by either a transfer process [12] or direct deposition [13]. We present here how to find a suitable combination of these parameters to obtain nanocrystalline silicon at high growth rates $(>5 \mathrm{~nm} / \mathrm{s})$. Further optimizations are achieved by identifying the so called crystalline to amorphous transition regime, letting the gas distribution in the plasma zone by a suitable showerhead design 
and finding a deposition process that avoids the progress towards the dusty plasma regime. Amplitude modulation of the RF plasma is proposed as a candidate to achieve the last case. We will show how various diagnostic tools, such as optical emission spectroscopy (OES), voltage-current $(V-I)$ impedance probe and ion energy analyzer can be used in the optimization process to obtain state of the art nc-Si as well as a-Si solar cells with high deposition rates and/or at low temperatures.

\section{Experimental}

Most of the depositions of thin film silicon samples, which vary from amorphous to nanocrystalline silicon and the solar cells that employed these samples were made in an ultra high vacuum multichamber deposition system called ASTER [14] using VHF PECVD technique at 50 or $60 \mathrm{MHz}$ frequency. The in situ monitoring tools, such as OES and $V-I$ probe were fitted to the reactor to record and monitor the gas phase processes and the delivered power to the reactor respectively. Some of the samples were deposited in ATLAS high vacuum system with a reactor that is a replica of the reactors in ASTER system. ATLAS is equipped with a UV-vis spectroscopic ellipsometer to monitor the growth process and quality of the grown material and a retarding field ion energy analyzer to probe ion energy and flux of the ions reaching the growing surface. Solar cells made in ASTER system were analyzed by current-voltage measurement using a calibrated dual beam solar simulator (Wacom, Japan).

\section{Results and discussion}

\subsection{High deposition rate $\mathrm{nc}-\mathrm{Si}$}

A combination of a high frequency $(60 \mathrm{MHz})$, an RF power of $15 \mathrm{~W}$ and a pressure of $5 \mathrm{mbar}$ and a novel gas showerhead has delivered a high stabilized efficiency of $10 \%$ for an nc-Si cell in a $\mathrm{p}-\mathrm{i}-\mathrm{n}$ configuration. These cells also turned out to be very stable without suffering from any degradation under AM1.5 light soaking. The deposition rates of these films were already reasonably high $(0.5 \mathrm{~nm} / \mathrm{s})$. However, increasing the deposition rate further to ultra high values $(>5 \mathrm{~nm} / \mathrm{s}$ ) needed an increase of the pressure to $9 \mathrm{mbar}$ and the RF power up to $400 \mathrm{~W}$. In situ diagnosis (OES) was used to carry out the optimization process. A simultaneous increase of the power and the flow rate in order to maintain similar depletion conditions has been found as a process to achieve this goal. We report below that this process needs a cautious approach and supplementary methods are needed to arrive at an optimum deposition condition. This is mainly due to our presumption that (i) intensities of hydrogen and silicon lines in OES sufficiently describe the condition for nanocrystalline growth and that (ii) increasing the pressure is sufficient to keep the ion energy at a desired level for the growth of device quality nc-Si material.

\subsubsection{Transition material}

One of the important optimization steps for nc-Si material is to find the so called transition regime [15], where the material is of best device quality. To obtain an accurate description of the dependence of plasma characteristics on the deposition conditions it is necessary to estimate the real coupled power. In ASTER the $V-I$ probe is used in the VHF PECVD reactor for the measurement of the actual delivered power to the discharge. This is much more accurate compared to the traditional method of monitoring the reflected power at the generator, since it is not affected by power lost in cables and matching network. The phase between the RF voltage and the current reflects whether the plasma is more capacitive or reactive. Since the impedance of the discharge may vary consider- ably when the regime is tuned from a pure silane discharge to a pure hydrogen discharge, these power losses are not merely a constant factor, which is also evident from the fact that the settings of the matching network need to be adjusted for every change in gas mixture. Furthermore, from the recorded data the resistivity of the plasma can be calculated, which is an indicator for particle formation and dust generation in the reactor. The impedance of the reactor was found to be inversely proportional to the distance between the electrodes that confirms the functioning of the $V-I$ probe. The plasma was characterized by OES in which the light emission of $\mathrm{Si}^{*}, \mathrm{SiH}^{*}, \mathrm{H}_{\alpha}$ and $\mathrm{H}_{\beta}$ species are monitored. At low pressure (1.1 mbar) conditions the $\mathrm{Si}^{*}$ intensity is proportional to the growth rate; whereas the $\mathrm{H}_{\alpha} / \mathrm{Si}^{*}$ ratio is considered as a finger print for determining the phase of the material (amorphous or nanocrystalline) [16]. We studied the variation of two deposition parameters for the growth process of silicon films, namely the hydrogen to silane flow ratio (hydrogen dilution) and the delivered power and compared the case of high pressure condition to the low pressure one.

In the first case the actual delivered power was fixed and the hydrogen dilution was varied. At low pressure (1.1 mbar) conditions, the plasma remained predominantly capacitive and the phase remained almost invariant with variation in hydrogen dilution in a wide range (1-45), whereas in high pressure conditions the plasma became more resistive as the hydrogen dilution was decreased (Fig. 1). These characteristics call for good monitoring of applied power to the plasma by the $V-I$ probe, as the power dissipation in the plasma will be influenced by the resistive component. For a typical case of $375 \mathrm{~W}$ delivered power and a pressure of $9 \mathrm{mbar}$, the impedance showed a monotonic decrease with hydrogen dilution, and a concomitant increase in electron temperature $\left(\mathrm{H}_{\beta} / \mathrm{H}_{\alpha}\right)$. The increase of the $\mathrm{H}_{\alpha} / \mathrm{Si}^{*}$ ratio with increasing hydrogen dilution predicts increased probability of crystal nucleation and nanocrystalline growth.

For the study of the effect of delivered power on plasma condition, the pressure ( 9 mbar) and hydrogen dilution were kept fixed. The atomic hydrogen concentration increased linearly with increased delivered power, whereas the $\mathrm{Si}^{*}$ intensity varied little (Fig. 2). On the other hand the deposition rate was found to increase monotonically with increasing power, showing no correlation with the OES emission from the $\mathrm{Si}^{*}$. This behavior contradicts our findings at low pressure conditions where a linear relationship between the $\mathrm{Si}^{*}$ intensity and the deposition rate has been observed [16]. The most likely explanation is that, due to the depletion, the primary dissociation rate of silane does not vary with increasing power for the high pressure case, whereas the concentration of silyl

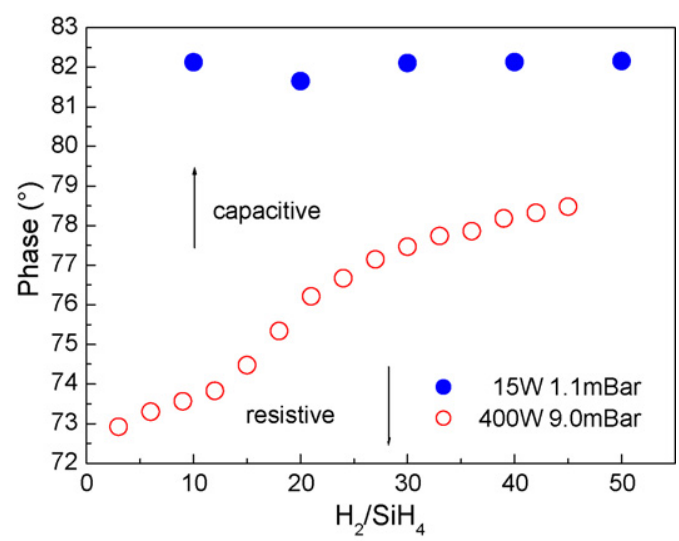

Fig. 1. Dependence of the phase of the plasma on hydrogen dilution conditions at two deposition rate conditions. 


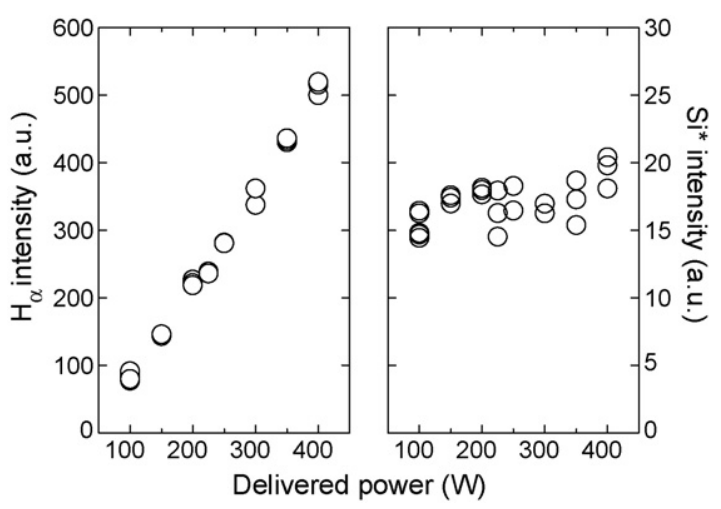

Fig. 2. Variation of the intensity of hydrogen and silicon lines in OES at high power conditions.

species increases due to hydrogen abstraction reaction in the gas phase.

$\mathrm{SiH}_{4}+\mathrm{H} \rightarrow \mathrm{SiH}_{3}+\mathrm{H}_{2}$

The increased hydrogen concentration at high power is attributed to the increased dissociation of hydrogen molecules. The OES data thus showed an increasing $\mathrm{H}_{\alpha} / \mathrm{Si}^{*}$ ratio at high powers.

The above result already suggests that $\mathrm{H}_{\alpha} / \mathrm{Si}^{*}$ at such high powers overestimates the relative fraction of atomic hydrogen reaching the growing surface. In fact a higher $\mathrm{H}_{\alpha} / \mathrm{Si}^{*}$ ratio of 13 was observed for the amorphous to nanocrystalline transition (Fig. 3b) [17]. This is somewhat higher than the threshold of $\mathrm{H}_{\alpha} / \mathrm{Si}^{*}$ of 8 (Fig. 3a) observed for transition in case of low pressure ( $1.1 \mathrm{mbar}$ ) condition. A computer simulation using a fluid model (details of which will be published elsewhere) supports this finding. The number of hydrogen atoms reaching the growing surface per deposited $\mathrm{Si}$ atom is proposed as a better indicator for the transition and this can be predicted by the simulation. The computer prediction, $\mathrm{H} / \mathrm{Si}>12$ (that reach the substrate) for nc-material, was confirmed through experiment. Table 1 shows in a case where the emission ratio $\mathrm{H}_{\alpha} / \mathrm{Si}^{*}$ is 12.5 , but the sample is amorphous, while on the other hand, the 2nd sample has an $\mathrm{H}_{\alpha} / \mathrm{Si}^{*}$ ratio of 5.2, though it is highly crystalline (80\%). The phase of both these cases was predicted by the simulations which showed that for the 1 st case the $\mathrm{H}$ to $\mathrm{Si}$ ratio reaching the substrate was below the threshold whereas the case is opposite for 2nd sample. The experimental method to achieve this optimization process was predicted [18] by taking the depletion parameter into account as a good indicator fore crystalline growth as explained below.

It is observed that as the deposition rate is increased at constant dilution (increasing the power and the total gas flow), maintaining the $\mathrm{H}_{\alpha} / \mathrm{Si}^{*}$ emission ratio is itself not sufficient to achieve the
Table 1

Two samples showing phase that is opposite to what the OES suggests, but agrees with the simulation prediction.

\begin{tabular}{llclcrc}
\hline Sample & Pressure & $\begin{array}{l}\text { Silane } \\
(\mathrm{sccm})\end{array}$ & $\begin{array}{l}\text { Hydrogen } \\
(\mathrm{sccm})\end{array}$ & Power $(\mathrm{W})$ & $\mathrm{H}_{\alpha} / \mathrm{Si}^{*}$ & $\begin{array}{l}\text { Raman } \\
\text { (cryst. frac.) }\end{array}$ \\
\hline A3115 & 9 mbar & 20.0 & 500.0 & 200.0 & 12.5 & $\sim 0 \%$ \\
A3227 & 6 mbar & 1.2 & 100.0 & 15.0 & 5.2 & $\sim 80 \%$ \\
\hline
\end{tabular}

desired crystallinity. So we have introduced another technique to accurately find a parameter to describe the optimum deposition condition. We call this parameter the "gas utilization parameter". This quantity is defined as $c_{\mathrm{d}}=$ deposition rate/silane gas flow rate, which basically is a measure for the depletion condition [18]. By adjusting the total flow rate the depletion can be maintained at a desired level (which is estimated in our case to be $0.29 \mathrm{~nm} / \mathrm{s} / \mathrm{sccm}$ ) and the required crystalline fraction is restored. By this method device quality nc-Si material was made at $5 \mathrm{~nm} / \mathrm{s}$ which delivered $6.4 \%$ efficiency. We think this new parameter (gas utilization parameter) is an important concept for nc-Si depositions in the high pressure depletion regime.

The above two studies show that the amorphous to nanocrystalline phase transition can be achieved through either increasing the hydrogen dilution or increasing the power. Films made with these parametric variations indeed showed the phase change from amorphous to nanocrystalline, as characterized by the activation energy of electrical conductivity and estimation of crystalline fraction from the Raman spectra. Our study also confirmed that similar to the behavior at low pressure conditions, the $\mathrm{H}_{\alpha} / \mathrm{Si}^{*}$ ratio (though at a higher value at high pressure conditions) is an indicator of the phase of the material and a threshold value of it is needed for the onset of nucleation and nanocrystalline growth.

\subsubsection{Pressure and inter electrode distance}

In order to increase the deposition rate the RF power has to be increased, which leads to an increase in ion energy. Nanocrystalline silicon films deposited under high energy ion bombardment tend to be very defective and such a process should be avoided to make device quality nc-Si material [19]. Hence, to compensate the adverse effect of high power on ion energy an increase in pressure is needed. The ions are cooled in such a gas phase condition due to loss of energy by multiple collisions. Another positive effect is that the high pressure condition can also lead to an increase in the number of growth precursors due to collisions. If the interelectrode distance is kept constant, the $\mathrm{Si}^{*}$ intensity increases with increasing pressure to reach a maximum and thereafter decreases $[16,20]$. In the mean while the $\mathrm{H}_{\alpha} / \mathrm{Si}^{*}$ ratio continuously decreases with increase in pressure. The power can be increased at such high pressure conditions to bring the plasma to a more depleted condition and this leads to a high deposition rate as well as increased
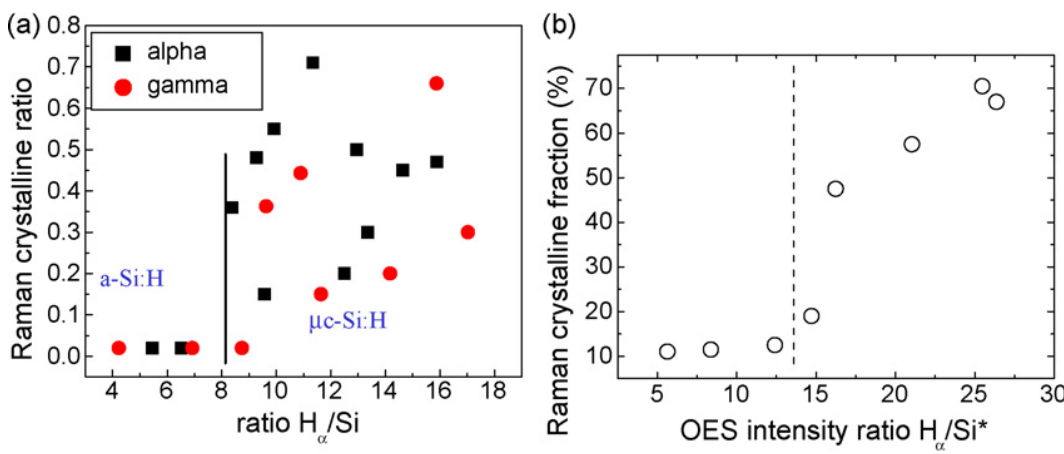

Fig. 3. The amorphous to crystalline transition at low (a) and high pressure (b) conditions. 

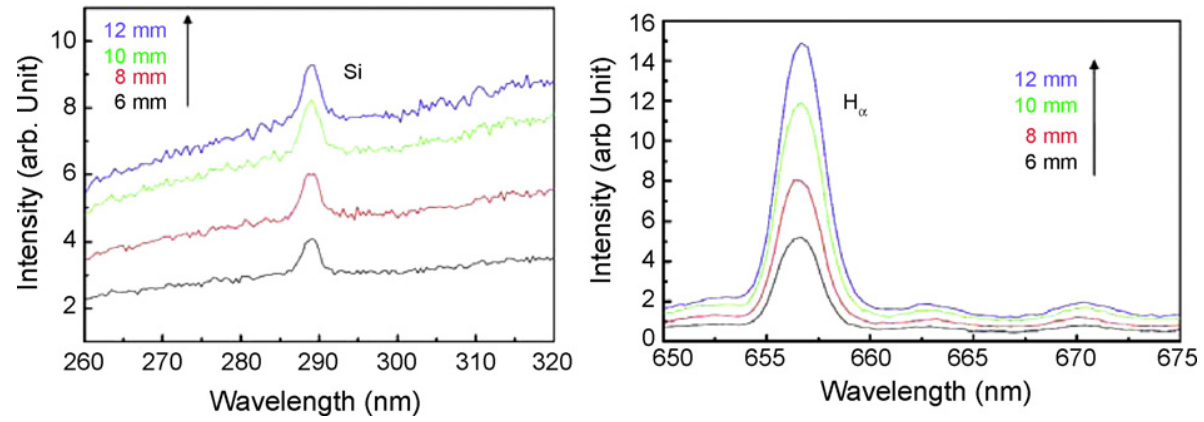

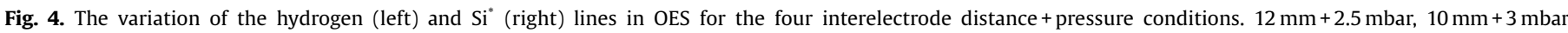
$8 \mathrm{~mm}+3.8 \mathrm{mbar}$ and $6 \mathrm{~mm}+5 \mathrm{mbar}$

atomic hydrogen concentration. However, increasing the pressure and power to such high levels results in increased gas phase reactions that result in higher silicon radicals and dusts. This will have an adverse effect not only on the material quality but also on the device performance using silicon materials made by such a method. A solution to this problem can be found by decreasing the inter electrode distance to decrease the amount of gas phase reactions. The consequence of this optimization step is that the distance between the electrodes come down from $\sim 20 \mathrm{~mm}$ for the deposition of optimum quality nanocrystalline silicon at low deposition rates $(0.1 \mathrm{~nm} / \mathrm{s})$ to near $6 \mathrm{~mm}$ for a high deposition rate material $(5 \mathrm{~nm} / \mathrm{s})$. This optimization process can be in situ analyzed by OES to understand how the deposition process is affected by changing pressure and inter-electrode distance simultaneously. In order to keep the plasma conditions comparable, the product of pressure and distance (pd) was kept constant. Fig. 4 shows the $\mathrm{H}_{\alpha}$ and $\mathrm{Si}^{*}$ emission lines for the case of 4 inter-electrode distances, $6 \mathrm{~mm}, 8 \mathrm{~mm}, 10 \mathrm{~mm}$ and $12 \mathrm{~mm}$ with the corresponding pressures 5 mbar, 3.8 mbar, 3.0 mbar and 2.5 mbar respectively. The applied power was kept constant for all the cases as monitored by the $V-I$ probe. It is observed that there is a small increase in $\mathrm{Si}^{*}$ intensity with decrease in pressure, which explains the increase in deposition rate, whereas the $\mathrm{H}_{\alpha}$ intensity increases by more than a factor of 2.5. We thus observe a continuous increase of $\mathrm{H}_{\alpha} / \mathrm{Si}^{*}$ ratio with decrease in pressure. This is reflected by the increases in Raman crystalline fraction from 0.44 to 0.66 . This effect could be attributed to a decrease of the electron temperature and/or hydrogen loss due to the abstraction reaction at the high pressure conditions. An interesting observation is that the deposition rate increases from $0.45 \mathrm{~nm} / \mathrm{s}$ to $0.62 \mathrm{~nm} / \mathrm{s}$ while going from $5 \mathrm{mbar}+6 \mathrm{~mm}$ to $2.5 \mathrm{mbar}+12 \mathrm{~mm}$ condition.

\subsection{Low deposition temperature}

The growth of silicon films by a CVD process needs certain external energy both for the production of growth precursors by dissociation of silicon containing gases and the surface reactions. In a thermal CVD process, the heat energy is used for the pyrolitic dissociation of gasses as well as the surface reactions. In a low pressure PECVD process, being a non-thermal equilibrium case, the electron temperature is very high whereas the ion temperature remains same as the cold gas temperature. The high electron temperature basically does the job of electron impact dissociation of molecules and the substrate temperature is optimized so as to give sufficient energy for the surface reactions. For an amorphous silicon case the optimum substrate temperature has been found to be around $200^{\circ} \mathrm{C}$ [21], which is a balance between the diffusion length of the growth precursors on the growing surface and the hydrogen evolution from the growing surface. The same concept holds good for the HWCVD and photo-CVD growth processes where the dissociations of molecules are done by a catalyst and the light respectively. This allows a much lower substrate temperature to be used than the thermal CVD. However, the additional local heat generated from the interaction of gas species at the growth surface has a crucial role in determining the quality of the films. For all of these cases the chemical annealing by atomic hydrogen takes place, whereas a PECVD process provides further extra energy through the energetic ions. Spectroscopic ellipsometry gives a good indication on the contributions of temperature, ions and hydrogen on the compactness of the film. We simulated the dielectric function of the films by using dispersion laws where the dielectric function is described by Tauc-Lorentz dispersion law [22].

The imaginary part of the dielectric function in a TL model is described by,

$\varepsilon_{\mathrm{im}}(E)=\frac{A E_{0} C\left(E-E_{\mathrm{g}}\right)^{2}}{\left(E^{2}-E_{\mathrm{g}}\right)^{2}+C^{2} E^{2}} \frac{1}{E}, \quad E>E_{\mathrm{g}}$

$\varepsilon_{\text {im }}(E)=0, \quad E \leq E_{\mathrm{g}}$

where $E_{0}$ is the peak transition energy, $E_{\mathrm{g}}$ is the gap energy, $C$ is a broadening parameter, and $A$ is related to the film compactness [22]. A sample made at $100^{\circ} \mathrm{C}$ is found to be less compact compared to that at $200^{\circ} \mathrm{C}$, both made by PECVD with pure silane (comparing the top two rows in Table 2). An interesting observation comparing the two samples (last two rows) made at similar substrate temperature of $\sim 100^{\circ} \mathrm{C}$, similar deposition rates $(0.13 \mathrm{~nm} / \mathrm{s}$ for the VHF PECVD layer and $0.11 \mathrm{~nm} / \mathrm{s}$ for the HWCVD layer) and similar deposition pressure conditions ( $0.1 \mathrm{mbar}$ for HWCVD and $0.16 \mathrm{mbar}$ for VHF PECVD) is that the VHF PECVD sample is more dense, which can be attributed to the beneficial aspect of ion energy.

To further understand the effect of ion energy on the structure of materials made at low substrate temperatures, the ion energy distribution functions (IEDF) have been measured by means of a 4 -grid electrostatic energy analyzer with retarding field. Experiments have been done at two frequencies $50 \mathrm{MHz}$ and $60 \mathrm{MHz}$ and similar results have been obtained for both the frequencies. Fig. 5 shows the effect of hydrogen dilution on the ion energy. For any $\mathrm{SiH}_{4}+\mathrm{H}_{2}$ gas mixture condition, the ion energy is less at the lower substrate temperatures. As the deposition rate changes very little with the change of substrate temperature for any fixed hydrogen

Table 2

Parameters obtained from the simulation of the ellipsometry data. $\mathrm{R}: \mathrm{H}_{2} / \mathrm{SiH}_{4}, \sigma_{\mathrm{SE}}$ : Surface roughness (ellipsometry), $E_{0}$ : Oscillator peak energy. $A$ is a parameter related to the compactness of the film.

\begin{tabular}{lllcll}
\hline Process & $T\left({ }^{\circ} \mathrm{C}\right)$ & $\mathrm{H}_{2} / \mathrm{SiH}_{4}$ & $\sigma_{\text {SE }}(\mathrm{nm})$ & $E_{\mathrm{o}}(\mathrm{eV})$ & $A$ \\
\hline PECVD & 200 & Pure silane & 4.3 & 3.62 & 209 \\
PECVD & 100 & Pure silane & 4.9 & 3.69 & 194 \\
VHF $^{*}$ & 100 & 20 & 4.7 & 3.62 & 206 \\
HWCVD $^{*}$ & 100 & 20 & 10.6 & 3.62 & 182 \\
\hline
\end{tabular}




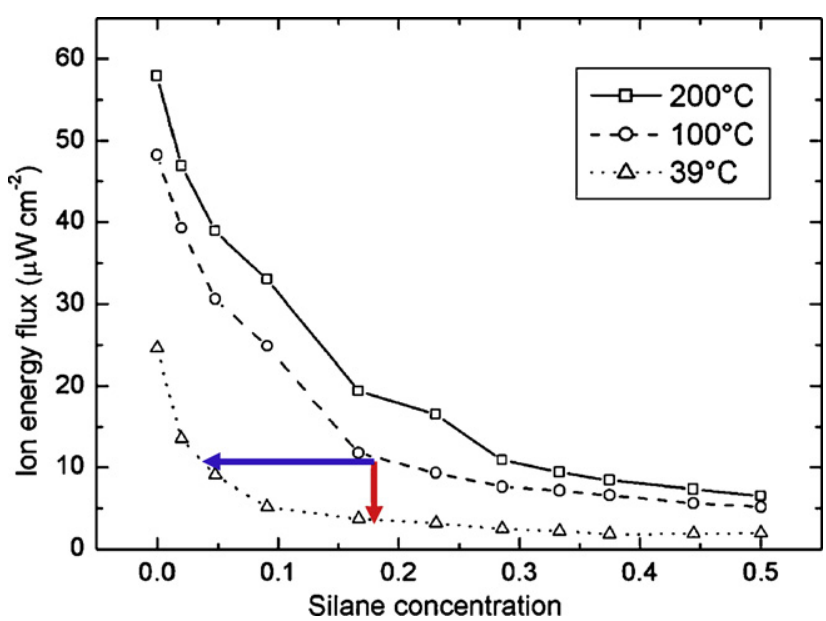

Fig. 5. Ion energy flux as function of silane fraction at indicated substrate temperatures.

dilution condition, we can infer that the ion energy per deposited species is reduced at the lower temperatures. This will lead to a decrease in the compactness of the films. This means that at the lower temperatures a PECVD process loses to some extent its advantage concerning the ion energy, if the gas phase conditions are not changed. However, the good news is that the ion energy is sensitive to the hydrogen dilution [23]. The peak in the ion energy distribution function constantly shifts to high energy with increasing dilution, whereas at very low dilution conditions, the peak is almost blurred due to increased collisions of ions with the other species. Hence, at low temperatures, the ion energy per deposited species can be increased by increasing hydrogen dilution and this extra energy can compensate the loss due to lower gas temperature. Indeed, the increase in ion energy per deposited species $\left(\mathrm{SiH}_{3}+\mathrm{SiH}_{2}\right)$ at high dilution conditions has been confirmed by the simulations using a fluid model for a gas temperature of $350 \mathrm{~K}$ [24]. We have shown here the need for increasing hydrogen dilution for the low substrate temperature growth for a reason that is very specific to a plasma enhanced deposition process. This extra benefit from the hydrogen dilution should be counted in addition to the chemical annealing that is relevant to all sorts of CVD deposition processes. We may also consider here that there are other methods to compensate the loss in ion energy, such as lowering the pressure, increasing the power and use of noble gasses such as $\mathrm{Ar}$ to deliver extra energy. We have only studied the hydrogen dilution conditions and how it should be adapted for different substrate temperature conditions to make the best device quality materials at various temperatures $[25,26]$. We have indeed observed that the dilution $\left(\mathrm{H}_{2} / \mathrm{SiH}_{4}\right)$ conditions are 1,15 and 40 respectively for 200 , 100 and $39^{\circ} \mathrm{C}$ substrate temperatures for the deposition of optimum quality a-Si. The photoresponse of the a-Si sample made at $100^{\circ} \mathrm{C}$ is $\sim 10^{6}$ which is comparable to the case of $200^{\circ} \mathrm{C}$ sample. With this optimum dilution condition, a respectable defect density of $2 \times 10^{16} / \mathrm{cm}^{3}$ and Urbach edge parameter of $55 \mathrm{meV}$ were obtained. Efficiency of $7.3 \%$ for a p-i-n type cell on Asahi u-type substrate and $5.3 \%$ for an n-i-p type of cell on smooth $\mathrm{Ag} / \mathrm{ZnO}$ coated stainless steel substrate have been obtained. The difference in behaviour of these cells made at $100^{\circ} \mathrm{C}$ compared to the $10 \%$ efficiency cells made at $200^{\circ} \mathrm{C}$, can be partly attributed the effect of substrate roughness on the shunting behaviour of the cell, an effect that limits the use of efficient scattering and optical confinement, that would give higher current density. Our experience on the low temperature deposited materials conveys the message that it is possible to obtain device quality materials down to very low temperatures, however, that is achieved at a cost of deposition rate which monotonically decreases with the increase in hydrogen dilution. With our understanding on the ion energy changes with temperature, we may propose that with alternate sources to enhance the ion energy such as high power, low pressure or $\mathrm{Ar}$ in the gas mixture, a comparatively lower hydrogen dilution can deliver the same device quality. This will help to maintain a high deposition rate at low substrate temperature.

\section{Conclusion}

Optical emission spectroscopy is a useful gas phase diagnostic tool for the deposition of thin film silicon, especially for predicting amorphous to nanocrystalline transition and the growth rate, however, this technique fails to deliver unambiguous prediction for nanocrystalline silicon films deposited at high pressure conditions to achieve high growth rates. In situ ion energy analysis also provides valuable information on the ion fux and ion energy which are critical parameters that define the properties of the material in a plasma enhanced deposition process. We found in this study that hydrogen dilution has an extra role than increasing reactions at the growing films, namely increasing the ion energy per deposited species. This characteristic is very beneficial for the deposition of silicon films at low substrate temperatures.

\section{Acknowledgements}

The authors gratefully acknowledge Caspar van Bommel for depositions and Ruurd Lof for technical support. This research was financially supported by the Netherlands Agency for Energy and the Environment (SenterNovem) of the Ministry of Economic Affairs: regeling Energie Onderzoek Subsidie: Lange Termijn' (EOS LT) and The Netherlands Organisation for Scientific Research (NWO).

\section{References}

[1] T. Tomita, Technical Digest of the International PVSEC-17, Fukuoka, Japan, 2007, p. 1.

[2] Y. Tsunomura, Y. Yoshimine, M. Taguchi, T. Kinoshita, H. Kanno, H. Sakata, E. Maruyama, M. Tanaka, Technical Digest of the International PVSEC-17, Fukuoka, Japan, 2007, p. 387.

[3] M. Reuter, W. Brendle, O. Tobail, J.H. Werner, Technical Digest of the International PVSEC-17, Fukuoka, Japan, 2007, p. 424 ( $\eta=17 \%$ for $50 \mu \mathrm{m}$ film by transfer method).

[4] G. Hahn, S. Seren, M. Kaes, A Schönecker, JP. Kalejs, C. Dubeř, A Grenko, C Belouet, Conference Record of the 2006 IEEE 4th World Conference on Photovoltaic Energy Conversion, WCPEC-4, vol. 1, 2007, p. 972.

[5] M. Gloeckler, Technical Digest of the International PVSEC-17, Fukuoka, Japan, 2007, p. 116.

[6] K. Matsunaga, T. Komaru, Y. Nakayama, T. Kume, Y. Suzuki, Technical Digest of the International PVSEC-17, Fukuoka, Japan, 2007, p. 455.

[7] M.A. Green, P.A. Basore, N. Chang, D. Clugston, R. Egan, R. Evans, D. Hogg, S. Jarnason, M. Keevers, P. Lasswell, J. O'Sullivan, U. Schubert, A. Turner, S.R. Wenham, T. Young, Solar Energy 77 (2004) 857.

[8] K. Yamamoto, A. Nakajima, M. Yoshimi, T. Sawada, S. Fukuda, T. Suezaki, M. Ichikawa, Y. Koi, M. Goto, T. Meguro, T. Matsuda, T.I. Sasaki, Y. Tawada, Conference Record of the 2006 IEEE 4th World Conference on Photovoltaic Energy Conversion, WCPEC-4, vol. 2, 2007, p. 1489.

[9] http://www.sharpnews.co.uk/?p=804.

[10] B. Yan, G. Yue, J.M. Owens, J. Yang, S. Guha, Conference Record of the 2006 IEEE 4th World Conference on Photovoltaic Energy Conversion, WCPEC-4, vol. 2, 2007, p. 1461.

[11] J.K. Rath, A. Verkerk, R. Franken, C. van Bommel, K. van der Werf, A. Gordijn, R. Schropp, Conference Record of the 2006 IEEE 4th World Conference on Photovoltaic Energy Conversion, WCPEC-4, vol. 2, 2007, p. 1473.

[12] J.K. Rath, Y. Liu, A. Borreman, E.A.G. Hamers, R. Schlatmann, G.J. Jongerden, R.E.I. Schropp, J. Non-Cryst. Solids 54 (2008) 2381.

[13] F.J. Haug, V. Terrazzoni-Daudrix, T. Söderström, X. Niquille, C. Ballif, Technical Digest of the International PVSEC-17, Fukuoka, Japan, 2007, p. 335

[14] C.A.M. Stap, H. Meiling, G. Landweer, J. Bezemer, W.F. van der Weg, Proceedings of the Ninth E.C. Photovoltaic Solar Energy Conference, Freiburg, 1989, p. 74.

[15] O. Vetterl, F. Finger, R. Carius, P. Hapke, L. Houben, O. Kluth, A. Lambertz, A. Muck, B. Rech, H. Wagner, Sol. Energy Mater. Sol. Cells 62 (2000) 97. 
[16] J.K. Rath, R.H.J. Franken, A. Gordijn, R.E.I. Schropp, W.J. Goedheer, J. Non-Cryst. Solids 338-340 (2004) 56.

[17] A.D. Verkerk, J.K. Rath, R.E.I. Schropp, Proceedings of 22nd EUPVSEC, Milaan, 2007, p.1843.

[18] A. Gordijn, M. Vanecek, W.J. Goedheer, J.K. Rath, R.E.I. Schropp, Jpn. J. Appl. Phys. 45 (2006) 6166.

[19] K. Keppner, U. Kroll, P. Torres, J. Meier, D. Fischer, M. Goetz, R. Tscharner, A. Shah, Proceedings of 25th IEEE Photovolt. Energy Conference, Washington, 1996, p. 669.

[20] L. Guo, M. Kondo, M. Fukawa, K. Saitoh, A. Matsuda, Jpn. J. Appl. Phys. 37 (1998) L1116.

[21] A. Matsuda, Jpn. J. Appl. Phys. 43 (2004) 7909

[22] J.K. Rath, R.E.I. Schropp, Pere Roca i Cabarocas, Phys. Stat. Sol. (c) 5 (5) (2008) 1346.
[23] A. Verkerk, J.K. Rath, M. Brinza, R.E.I. Schropp, W.J. Goedheer, V.V. Krzhizhanovskaya, Y.E. Gorbachev, K.E. Orlov, E.M. Khilkevitch, A.S. Smirnov, Symposium K: Advanced Silicon Materials Research for Electronic and Photovoltaic Applications, E-MRS 2008 Spring Meeting, Strasbourg (France), May 26-30, 2008 (this issue)

[24] J.K. Rath, A. Verkerk, M. Brinza, R.E.I. Schropp, W.J. Goedheer, V.V. Krzhizhanovskaya, Y.E. Gorbachev, K.E. Orlov, E.M. Khilkevitch, A.S. Smirnov, Proc. 33rd IEEE PVSC, San Diego, 2008.

[25] M. Brinza, J.K. Rath, R.E.I. Schropp, Sol. Energy Mater Sol. Cells (2008), doi:10.1016/j.solmat.2008.09.013.

[26] P.C.P. Bronsveld, J.K. Rath, R.E.I. Schropp, 20th EU PVSEC, Barcelona, 2005, p. 1675. 